\title{
Heterogeneity in combined immunodeficiencies with associated or syndromic features (Review)
}

\author{
LAVINIA CABA $^{1 *}$, CRISTINA GUG ${ }^{2 *}$ and EUSEBIU VLAD GORDUZA ${ }^{1,3^{*}}$ \\ ${ }^{1}$ Department of Medical Genetics, 'Grigore T. Popa' University of Medicine and Pharmacy, 700115 Iași; \\ ${ }^{2}$ Department of Microscopic Morphology, ‘Victor Babeş' University of Medicine and Pharmacy, 300041 Timisoara; \\ ${ }^{3}$ Prenatal Diagnosis Department, 'Cuza Voda' Obstetrics-Gynecology Clinical Hospital, 700038 Iași, Romania
}

Received September 14, 2020; Accepted October 14, 2020

DOI: $10.3892 /$ etm.2020.9517

\begin{abstract}
Primary immunodeficiencies are genetic diseases, mainly monogenic, that affect various components of the immune system and stages of the immune response. The category of combined immunodeficiencies with associated or syndromic features comprises over 70 clinical entities, characterized by heterogeneity of clinical presentation, mode of transmission, molecular, biological, mutational and immunological aspects. The mutational spectrum is wide, ranging from structural chromosomal abnormalities to gene mutations. The impact on the function of the proteins encoded by the genes involved is different; loss of function is most common, but situations with gain of function are also described. Most proteins have multiple functions and are components of several protein interaction networks. The pathophysiological mechanisms mainly involve: Missing enzymes, absent or non-functional proteins, abnormal DNA repair pathways, altered signal transduction, developmental arrest in immune differentiation, impairment of cell-to-cell and intracellular communications. Allelic heterogeneity, reduced penetrance and variable expressivity are genetic phenomena that cause diagnostic difficulties, especially since most are rare/very rare diseases, which is equivalent to delaying proper case management. Most primary immunodeficiencies are Mendelian diseases with X-linked or recessive inheritance, and molecular diagnosis allows the identification of family members at risk and the application of appropriate primary and secondary prevention measures in addition to the specific curative ones. In conclusion, recognizing heterogeneity and its sources is extremely important for
\end{abstract}

Correspondence to: Professor Eusebiu Vlad Gorduza, Department of Medical Genetics, 'Grigore T. Popa' University of Medicine and Pharmacy, 16 Universitatii Street, 700115 Iași, Romania

E-mail: vgord@mail.com

"Contributed equally

Key words: combined immunodeficiencies, molecular heterogeneity, gene mutations, abnormal molecular pathways, clinical heterogeneity current medical practice, but also for the theoretical value of improving biological and biomedical applications.

\section{Contents \\ 1. Introduction \\ 2. Molecular heterogeneity and biological processes \\ 3. Mutational heterogeneity \\ 4. Clinical heterogeneity and mode of inheritance \\ 5. Conclusions}

\section{Introduction}

Primary immunodeficiencies (PIDs) are rare, mostly monogenic genetic diseases that affect various components of the immune system and are characterized by pathological, clinical, and immunological diversity $(1,2)$. The prevalence of PIDs is approximately $4-10$ per $10^{5}$ live births (3).

The International Union of Immunological Societies (IUIS) recognizes the existence of 430 entities and 408 different genes involved. It classifies diseases into 9 categories: Immunodeficiencies affecting cellular and humoral immunity, combined immunodeficiencies with associated or syndromic features, predominantly antibody deficiencies, diseases of immune dysregulation, congenital defects of phagocyte number or function, defects in intrinsic and innate immunity, autoinflammatory disorders, complement deficiencies and phenocopies of inborn errors of immunity (4-6). Of these, combined immunodeficiencies with associated or syndromic features present high heterogeneity manifested at the molecular and mutational level. Biological processes involve different gene expression products, 'extraimmune' clinical symptoms characteristic of each syndrome, and many diseases present incomplete penetrance and variable expressivity. This combined immunodeficiencies are classified into 10 types: Immunodeficiency with congenital thrombocytopenia; DNA repair defects (immunodeficiencies affecting cellular and humoral immunity); thymic defects with additional congenital anomalies; immuno-osseous dysplasias; hyper 
IgE syndromes (hyperimmunoglobulin E syndromes or HIES); dyskeratosis congenita (DKC), myelodysplasia, short telomeres; defects of vitamin B12 and folate metabolism; ectodermal anhidrotic dysplasia with immunodeficiency (EDA-ID); and calcium channel defects (4).

Correct and early diagnosis is necessary to prevent complications and reduce mortality (7). The molecular diagnosis can be followed by early protective and curative interventions, but also by avoiding the usual interventions which in the case of certain PIDs can bring additional complications (for example use of DNA-radiomimetic drugs in radiosensitive PIDs) (8). It is estimated that $70-90 \%$ of patients with PID remain undiagnosed worldwide (9). The onset can be at any age, but early onset correlates negatively with the severity of the manifestations (7). In many cases, patients are consulted for recurrent infections, but the etiological diagnosis is delayed. There are studies that show that in the US the etiological diagnosis is delayed by up to 12.4 years (10). During all this time, negative consequences can appear in personal, social and professional life, so that the quality of life is profoundly altered $(3,7,11)$. In some cases, patients also have a predisposition to autoimmune diseases, autoinflammatory diseases or lymphoproliferative phenomena $(4,8,12-16)$.

\section{Molecular heterogeneity and biological processes}

The vast majority of genes involved are genes that encode proteins. In combined immunodeficiencies with syndromic features a double heterogeneity is present: A specific protein presents multiple and diverse molecular functions while several different proteins have the same molecular function. Table I summarizes the molecular functions of these proteins and the biological processes in which they intervene according to UniProt Knowledgebase https:/www.uniprot. org/ (4-6,17-23).

Some genes encode proteins that interact with chromatin, being implied in chromatin binding (DNMT3B, RNF168, POLE, STAT5B and KDM6A), chromatin DNA binding (STAT3, KDM6A) or chromatin regulation (CHD7, MYSM1, $K M T 2 D$ and $K D M 6 A)(23)$.

Other proteins interact with histones and allow histone binding (RNF168, MYSM1, WRAP53 and KMT2D), histone deacetylase binding (DNMT3B), histone demethylase activity [H3-K27 specific] (KDM6A) or histone methyltransferase activity [H3-K4 specific] (KMT2D and KMT2A) (23).

A major category is represented by genes that encode proteins implied in interaction with DNA: DNA binding (ZNF341, ATM, BLM, NFE2L2, DNMT3B, PMS2, POLE, POLE2, LIG1, ERCC6L2, TBX1, CHD7, FOXN1, MYSM1, STAT3, RTEL1, TERT, SP110 and KMT2D), DNA replication origin binding (MCM4), single-stranded DNA binding ( $B L M$, MCM4, STN1 and CTC1), or damaged DNA binding (NBN, DCLRE1B/SNM1/APOLLO) (23).

Other genes encode transcription factors implied in RNA polymerase II activity (TBX1, FOXN1, STAT3, STAT5B, $N F E 2 L 2, K M T 2 A$ and $B C L 11 B)$, DNA-binding transcription factor activity [ZBTB24, FOXN1, MYSM1, STAT3, SP110, STAT5B, KMT2D (MLL2), TBX1, ZNF341 and NFE2L2, $B C L 11 B]$ or transcription factor binding (NBN, TBX1, STAT3 and NFKBIA) (23).
The functions of telomeres are regulated by other genes that influence telomeric DNA binding (TERT, TINF2, STN1 and $C T C 1$ ), telomerase RNA binding (DKC1, NHP2, NOP10, TERT, PARN and WRAP53) or telomerase activity (TERT and DKC1) (23).

In addition, in immunodeficiencies different enzymatic activity may be disturbed: GTPase regulator activity (WAS), small GTPase binding (WAS), phospholipase binding (WAS), protein kinase binding (WAS, ERCC6L2, STAT3, PARN and $I K B K B)$, DNA-dependent protein kinase activity $(A T M)$, helicase (BLM , HELLS, MCM4, ERCC6L2, CHD7, SMARCAL1, RTEL1, SKIV2L), hydrolase (HELLS, PMS2, MCM4, POLE, ERCC6L2, CHD7, SMARCAL1, MYSM1, RTEL1, TPP1, DCLRE1B/SNM1/APOLLO, PARN and MTHFD1), nuclease (PMS2, POLE, DCLRE1B/SNMI/APOLLO and PARN), metalloprotease (MYSM1), phosphoglucomutase activity (PGM3), DNA polymerase binding (RTEL1) (23).

Another process that is perturbed in immunodeficiencies is ion binding and the main genes implied are TGFBR1, TGFBR2, ZNF341, DNMT3B, ZBTB24, RNF168, LIG1, MYSM1, EXTL3, RTEL1, TERT, TPP1, PARN, TCN2, IKBKG (NEMO), SP110, HOIL1 (RBCK1), RNF31, KMT2D (MLL2), KMT2D (MLL2), KDM6A, BCL11B, STIM1, FAT4 and CCBE1 (23).

The connection with RNA could be abnormal in immunodeficiencies because of an abnormal ribonucleoprotein (DKC1, NHP2, NOP10, TERT), RNA binding (DKC1, NHP2, NOP10 and WRAP53) or box H/ACA snoRNA binding (DKC1, NHP2 and NOP10) (23).

Other processes are disturbed because of gene mutations implied in protein binding (WAS, ATM, BLM, STAT3, TERT, IKBKB, WRAP53, IKBKG (NEMO), NFKBIA, ORAII, STIM1, PNP, HOIL1, KDM6A,KMT2A and IL6ST), Rac GTPase (WAS), SH3 domain binding (WAS, WIPF1), profilin binding (WIPF1), ATP binding [IKBKB, TGFBR], TGFBR2, ATM, BLM (RECQL3), HELLS, PMS2, MCM4, LIG1, ERCC6L2,SKIV2L, CHD7, SMARCAL1, RTEL1 and MTHFD1], chaperone binding (TERT and WRAP53), actin (actin filament) binding (WAS, WIPF1 and ARPC1B) (23).

Other genes, such as $R M R P, R N U 4 A T A C$ or TERC, encode noncoding RNA (part of RNase MRP), small nuclear RNA and telomerase RNA component (Table I). Mutations in these genes cause alterations in processing of ribosomal RNA. $R M R P$ gene mutations disturb mitochondrial DNA replication and cell cycle control. RNU4ATAC gene mutations produce defects of spliceosome complex. Mutations in the TERC gene are implied in dysfunctions of telomere length (19,22,24-26).

Genes including HELLS, TBX1, SEMA3E, FOXN1, $C C B E 1$ or $K D M 6 A$ encode proteins involved in development of one or more organs. The most illustrative example is the TBX1 gene that is involved in multiple biological processes: Angiogenesis, morphogenesis of cranial region, heart, parathyroid gland, pharyngeal system, soft palate, thymus or thyroid gland (23). Thus, deficiency in the $T B X 1$ gene, characteristic to velo-cardio-facial syndrome, explains the association of abnormalities in multiple systems. The $T B X 1$ gene allows thymus epithelium morphogenesis, lymphoid lineage cell migration into the thymus, regulation of positive thymic $\mathrm{T}$ cell selection and $\mathrm{T}$ cell homeostasis. Other developmental proteins are also involved in the genesis of various organs/components of the immune system. For example, the FOXN1 gene allows 


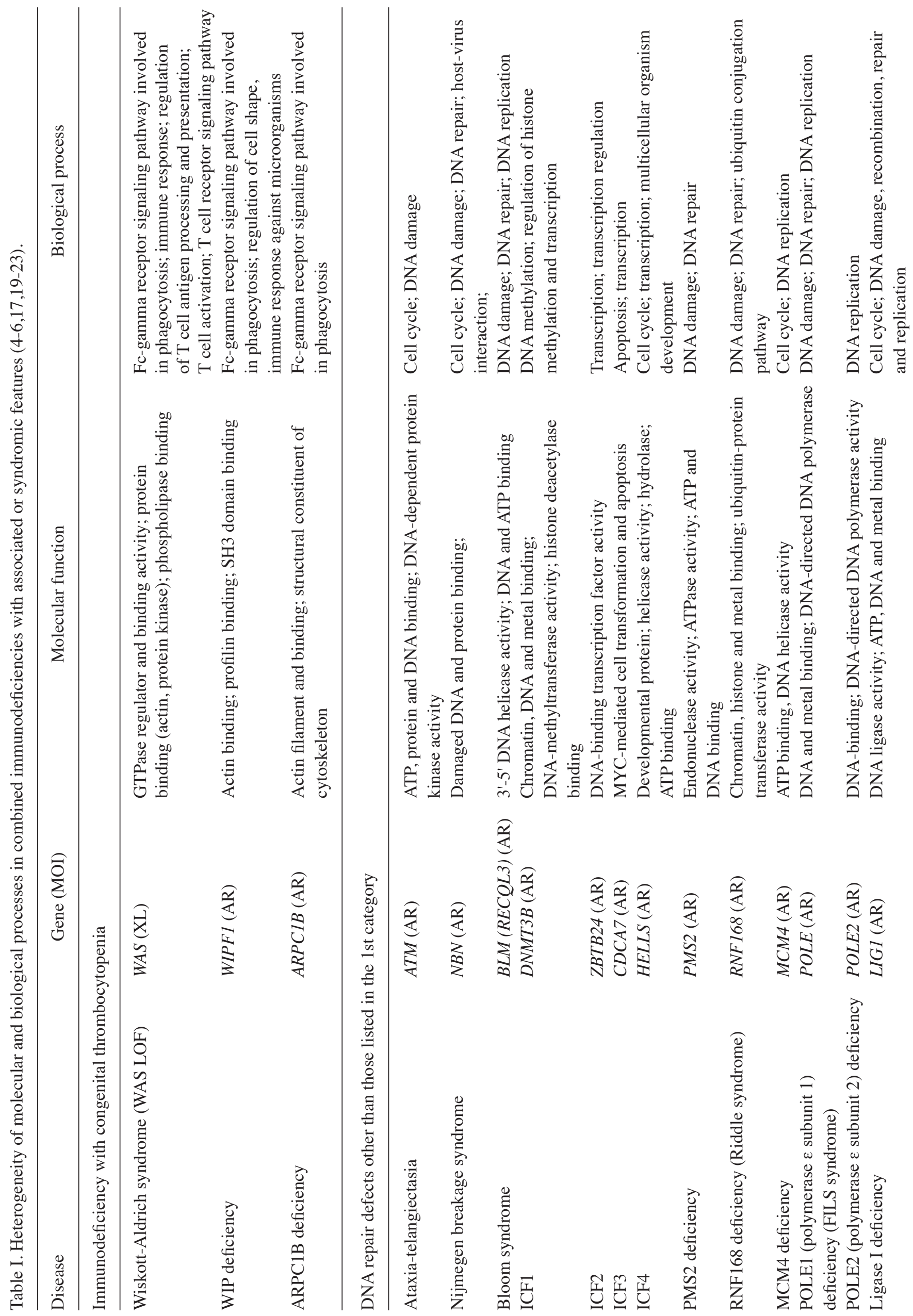




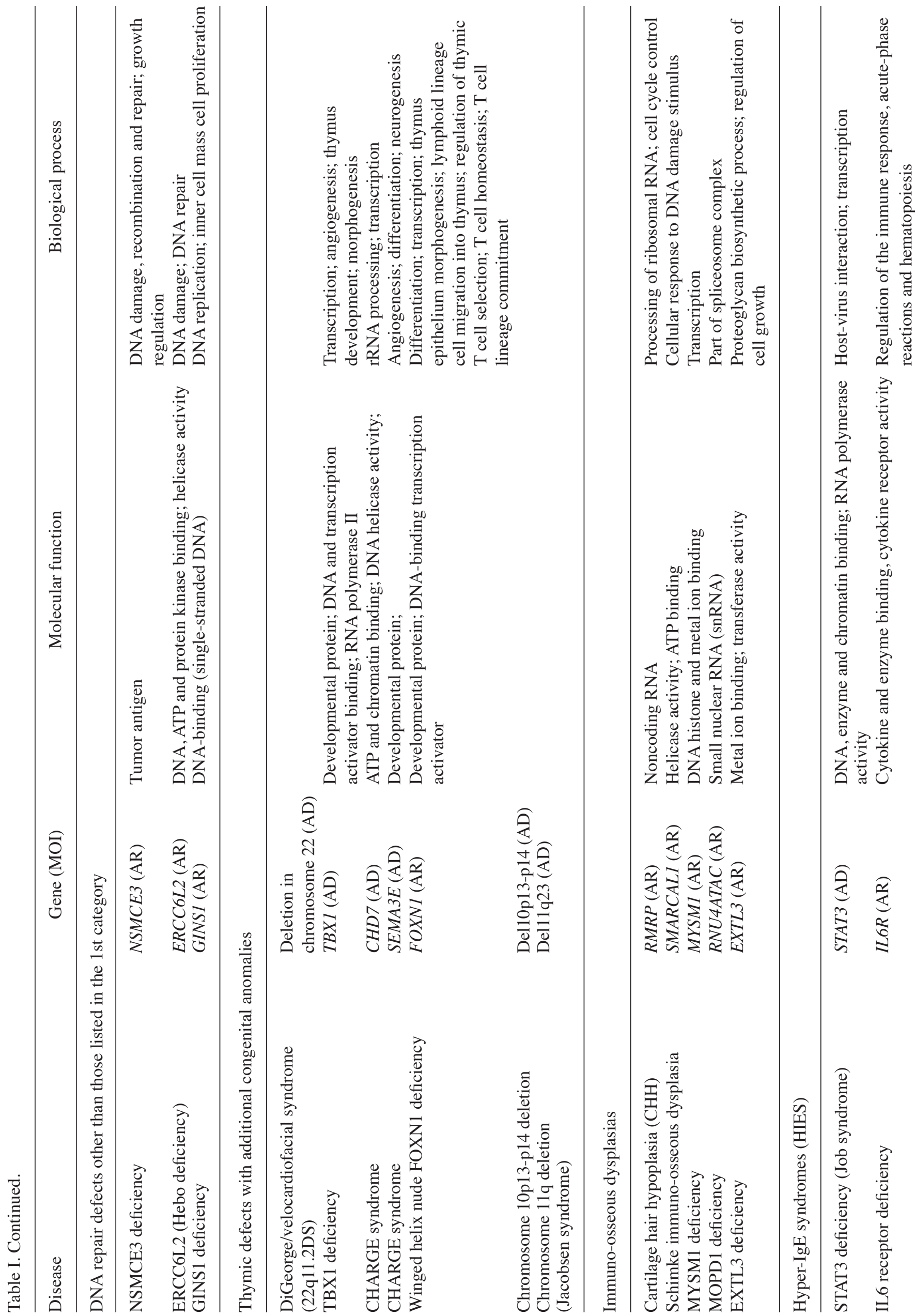




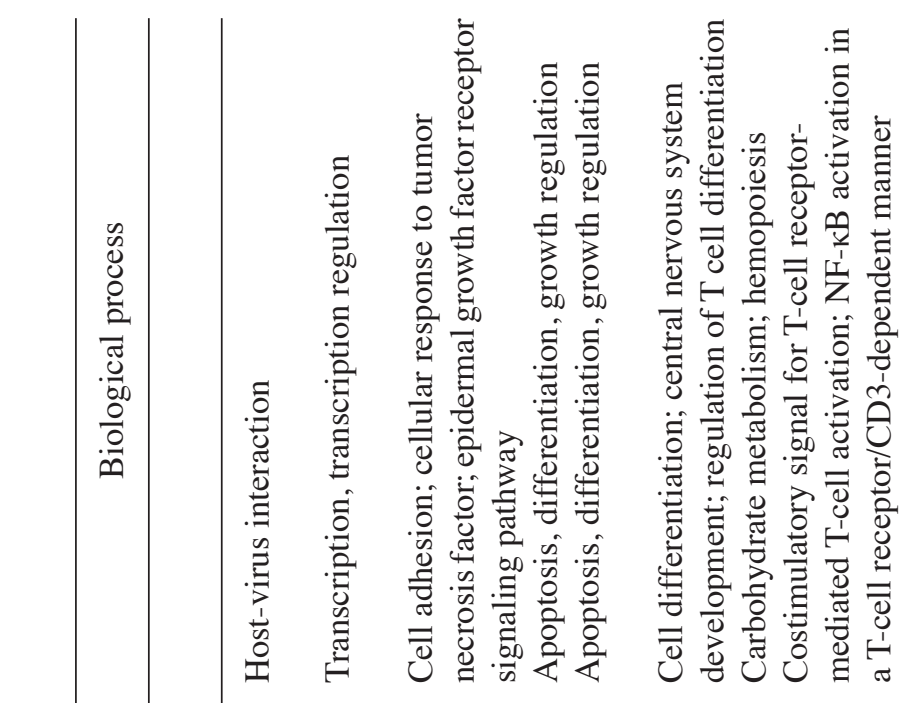

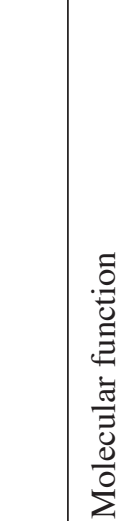

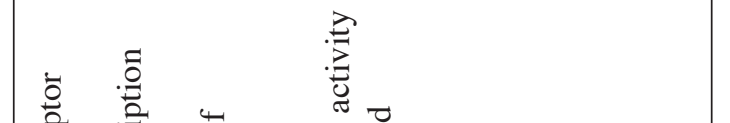

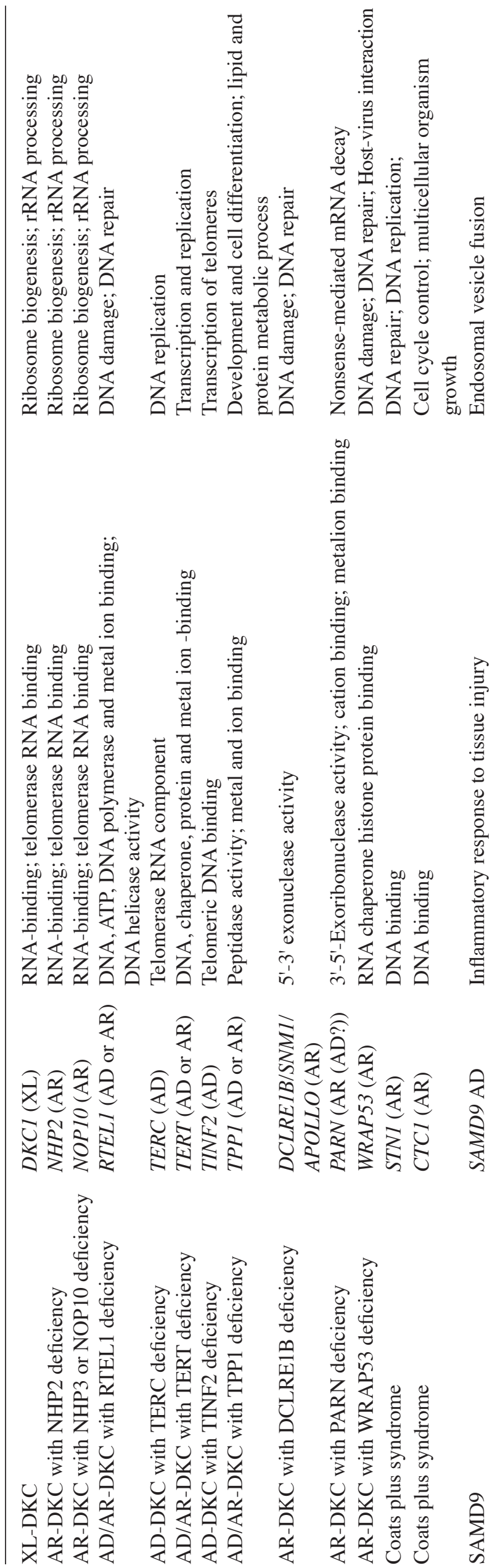




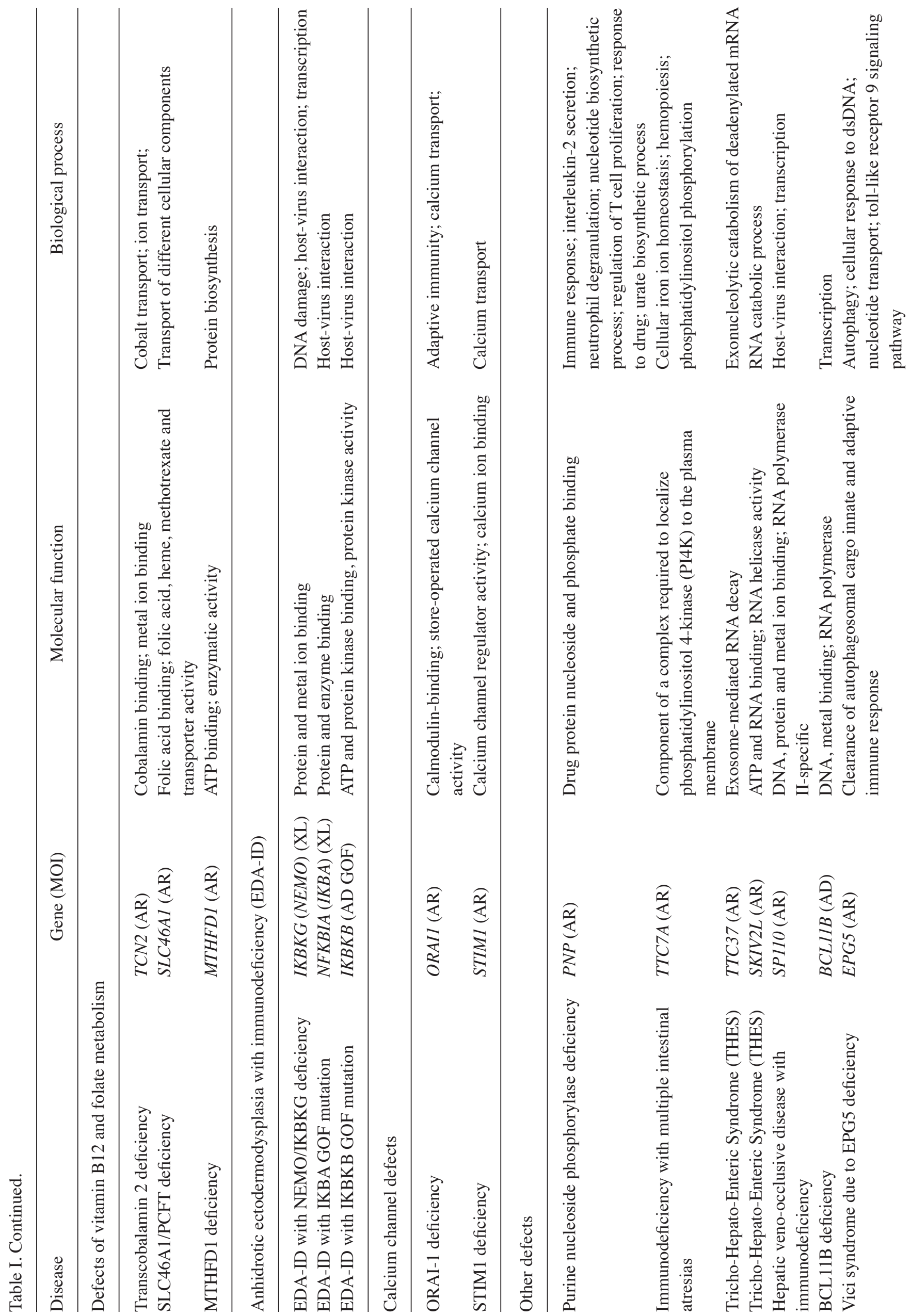




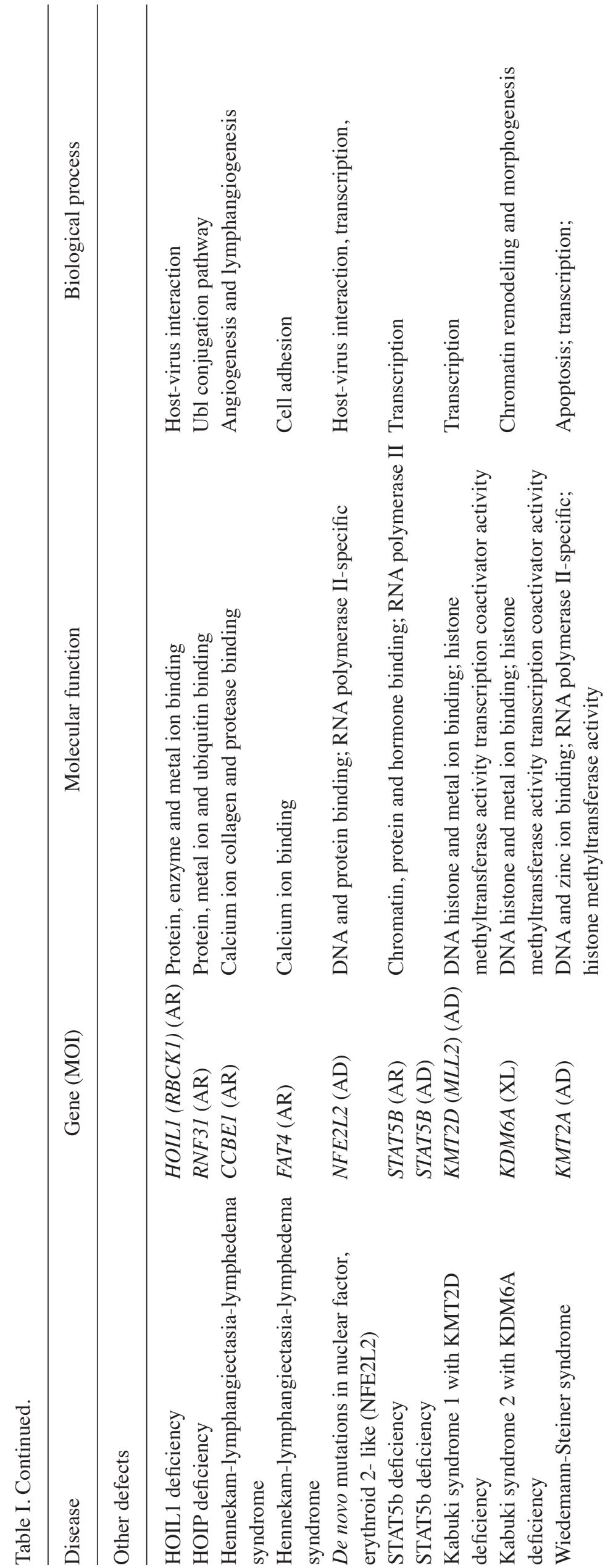

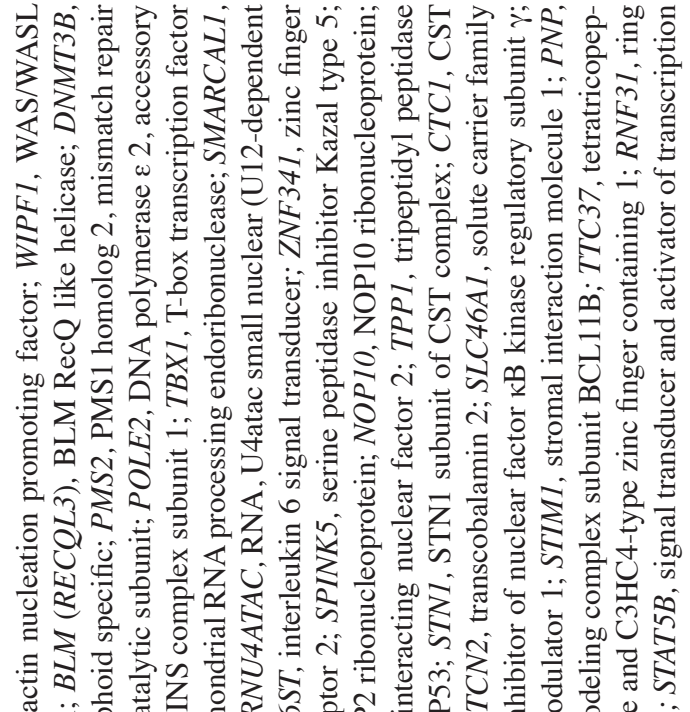

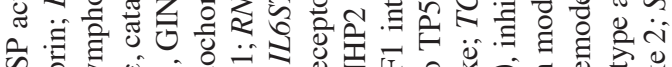

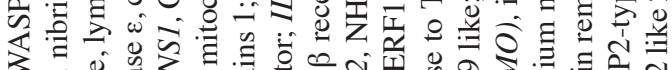

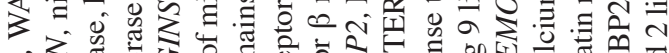

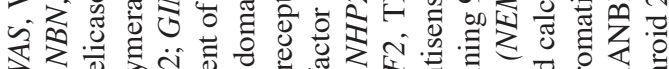

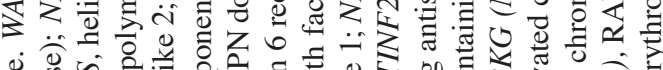
यं

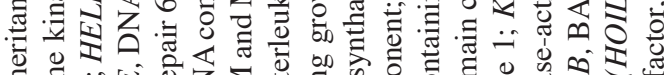

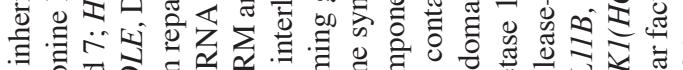

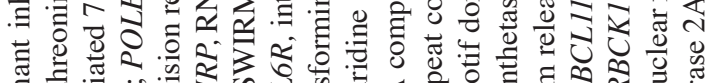

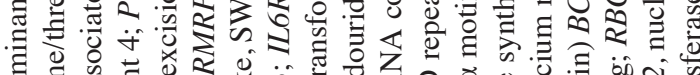

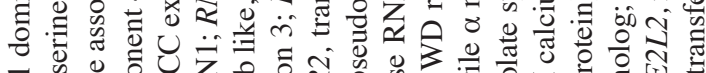

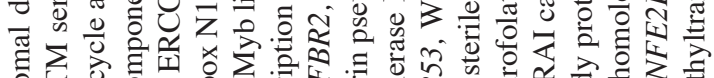

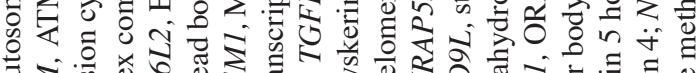

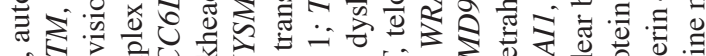

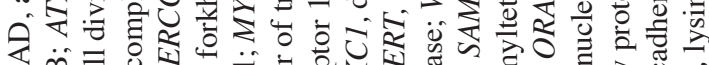

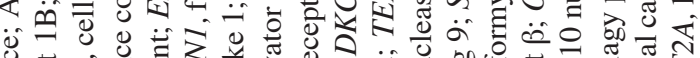

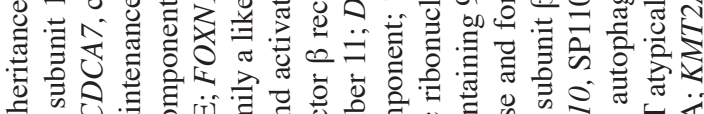

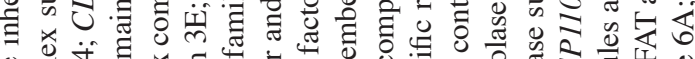

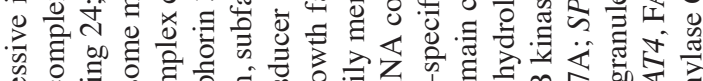

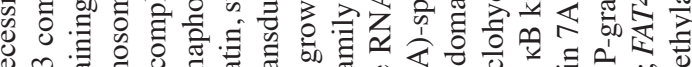

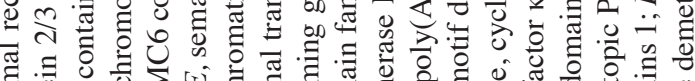

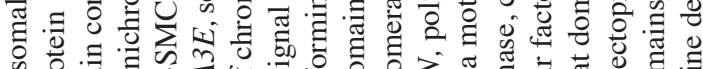

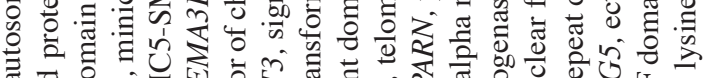

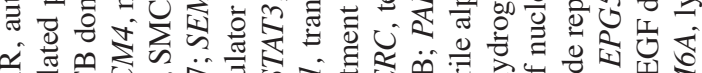

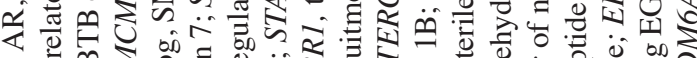

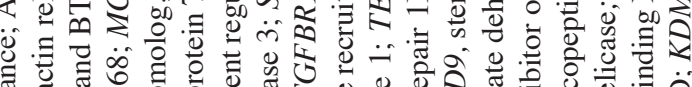

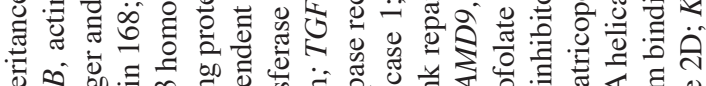

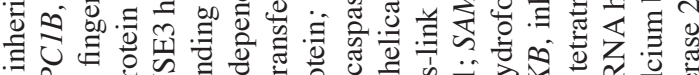

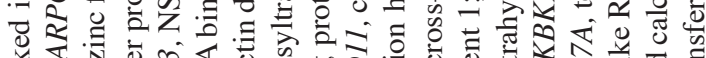

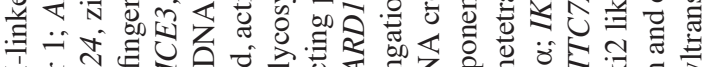
$\rtimes$ 过

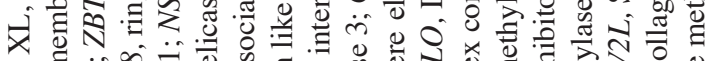
$\ddot{\theta} 0000$

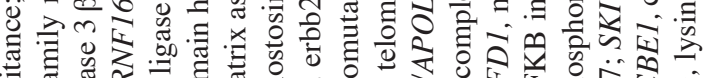

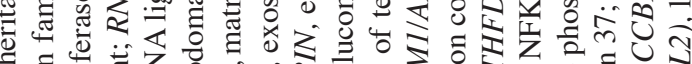

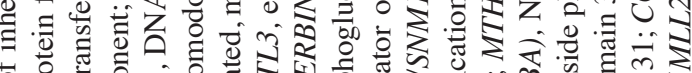

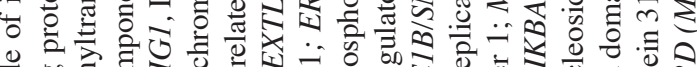

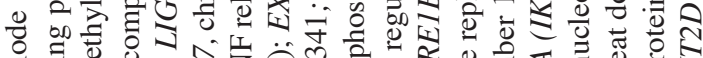

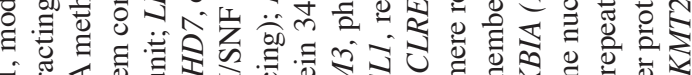

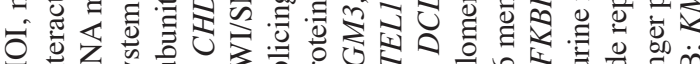


thymus epithelium morphogenesis, lymphoid lineage cell migration into the thymus, regulation of positive thymic $\mathrm{T}$ cell selection, $\mathrm{T}$ cell homeostasis and $\mathrm{T}$ cell lineage commitment (Table I) (19,22,24-26).

The pathogenic complexity of combined immunodeficiencies associated with syndromic features could be explained by the multiple interactions between the mentioned genes and important cell processes, such as the cell cycle, DNA damage, DNA repair process, DNA replication, apoptosis, transcription, cell division, multicellular organism development, ribosome biogenesis and processing, immune response, autophagy and cell adhesion. The pathophysiological mechanisms mainly involved are: Missing enzymes, absent or non-functional proteins, abnormal DNA repair, altered signal transduction, developmental arrest in immune differentiation, impairment of cell-to-cell and intracellular communications (Table I) $(19,22,24-26)$.

\section{Mutational heterogeneity}

The majority of combined immunodeficiencies with syndromic features are monogenic diseases caused by mutations in a pair of nuclear genes and only few diseases are caused by chromosomal microdeletions.

Most mutations are loss-of-function (LOF) mutations with a recessive pattern of transmission. Other mutations produce a gain of function (GOF). GOF mutations are almost always dominant (27). In some situations, for the same gene, distinct missense mutations may cause either LOF or GOF. An example of this is the STAT3 gene (28). STAT3 LOF mutation causes Job syndrome while STAT3 GOF mutation causes a form of immunodeficiency characterized by an immune deregulation. Thus, in such situations it is absolutely necessary to perform genetic testing to detect the mutation and its effect on the protein (29). All of these can influence also the treatment strategy. In STAT3 GOF the efficient treatment includes monoclonal antibody (mAb) against IL-6R and HSCRT, while in STAT3 LOF the most efficient treatment is the long term use of antibiotics and humanized recombinant monoclonal against $\operatorname{IgE}(30-32)$.

\section{Clinical heterogeneity and mode of inheritance}

Clinical heterogeneity is even greater as in the case of combined immunodeficiencies with syndromic features when it presents an interindividual and interfamilial variable expressivity, in correlation with the type of mutation. In such cases, identification of a specific association of abnormalities allows an early diagnosis, sometimes even before the onset of immune manifestations (33). In the majority of cases, immunodeficiency clinical signs are not specific such as infections, skin inflammation, hematologic autoimmune/autoinflammatory disorders, and different types of malignancy. Thus discovery of a particular non-immune feature becomes very helpful for a precocious diagnosis (33-35).

Usually, the onset of disease occurs in childhood, but retarded manifestations could be found in the case of a hypomorphic mutations or a random X-chromosome inactivation in women heterozygote for a X-linked recessive mutation $(33,36,37)$.
Infections observed in various primary immunodeficiency diseases can be bacterial, viral or fungal. Each infection has certain particularities. For example non-tuberculosis mycobacteria infections are found in $I K B K G, I K B K B$, GOF NFKBIA/IKBA deficiency; pyogenic pneumonia with pneumatocele formation and empyema/abscess and visceral abscess with $S$. aureus in childhood are specific for STAT3 deficiency; recurrent pyogenic sepsis is found in NEMO deficiency (33).

Viral infections with EBV (Epstein-Barr virus) and HHV8 (human herpes virus 8) - Kaposi sarcoma in young subjects are associated with STIM1 deficiency, AT (ATM), WAS (WASP), $\mathrm{CHH}(R M R P)$. Infection with HPV (human papilloma virus) with severe/recalcitrant warts, flat or verruca (often on trunk, face, neck, extremities, genital regions) are found in Netherton syndrome (SPINK5), WAS (WASP), NEMO deficiency $(I K B K G)$, AT $(A T M)$. Widespread molluscum contagiosum is associated with WAS, NEMO deficiency (IKBKG). Pneumonia with Pneumocystis jirovecii is present in WAS (WASP), NEMO deficiency (IKBKG), VODI (SP110), CARD11. Chronic mucocutaneous infection with Candida spp. is found in $I K B G$, $I K B A, I K B B, N E M O$ deficiency, VODI (SP110) and infection with Aspergillus spp. is specific for STAT3 deficiency (33).

In combined immunodeficiencies, various inflammatory skin conditions are found: Generalized exfoliative erythroderma of infancy in Comèl-Netherton syndrome (SPINK5); diffuse early-onset eczema and erythroderma and muscle amylopectinosis in HOIL-1 deficiency; severe early-onset atopic eczema in WAS, Comèl-Netherton syndrome, PGM3, STAT5b deficiencies, STAT3 deficiency; congenital livedo in FILS syndrome (POLE) (33).

Autoimmune/autoinflammatory disorders associated with primary immunodeficiencies include organ-specific autoimmunity (in $22 \mathrm{q}$ deletion syndrome, WASP, ATM, STAT5B mutations). Global hematologic autoimmunity changes have been observed in 22q deletion syndrome, PNP, STIM1, ORAII, WASP, ATM and STAT5B mutations while hematologic autoimmunity with non-virally induced lymphoproliferation have been associated with STIM1 deficiency, 22q11 deletion, 10p deletion. Other changes have been associated with sterile arthritis (WASP or STAT5B mutations); early-onset inflammatory bowel disease (WASP and $I K B K G$ mutations); trichohepatoenteric syndrome-SKIV2L and TTC37 mutations, Veno-occlusive disease with immunodeficiency (VODI) SP110 mutations; early-onset diarrhea and malabsorption from ICF-Immunodeficiency-centromeric instability-facial anomalies syndrome determined by mutations in DNMTB3, ZBTB24, CDCA7 and HELLS genes) $(33,38)$.

An increased risk of certain malignancies has been found in certain immunodeficiency syndromes. Various DNA repair deficiencies $(A T M, N B N, L I G 1)$ are associated with mainly lymphomas. MCM4 deficiency predisposes to EBV-associated lymphomas; Wiskott-Aldrich syndrome with myelodysplasia, leukemias and lymphomas. HHV8 is associated with primary Kaposi sarcoma (TNFRSF4, IFNGR1, WAS and STIM1); $\mathrm{CHH}$ $(R M R P)$ with an increased risk of basal cell carcinoma and of EBV-associated lymphoproliferation (25,33,39-45).

In combined immunodeficiencies with syndromic features all type of monogenic transmission have been identified. Pedigree analysis is an easy-to-use tool available to any 
practitioner to establish this fact. However, some genetic phenomena, such as low frequency of the disease (some of the immunodeficiencies are extremely rare diseases), incomplete penetrance of the disease, variable expressivity and de novo mutations, can complicate the process of identification of the type of transmission. A special situation is the allelic heterogeneity encountered for example in the case of Kabuki syndrome $(\mathrm{KS})$ : KMT2D-related $\mathrm{KS}$ is inherited in an autosomal dominant manner while KDM6A-related $\mathrm{KS}$ is inherited in an X-linked manner (45). There is also the variant in which mutations in a gene determine a condition that can be transmitted differently; STAT5b deficiency can be transmitted in an autosomal recessive or in an autosomal dominant model (33).

\section{Conclusion}

In conclusion, recognizing heterogeneity and its sources is extremely important for current medical practice, but also for the theoretical value of improving biological and biomedical applications.

\section{Acknowledgements}

Not applicable.

\section{Funding}

Not applicable.

\section{Availability of data and materials}

All data and materials supporting the results of the present study are available in the published article and supported by relevant references.

\section{Authors' contributions}

All three authors contributed equally to preparing the review and the data search and collection. LC carried out the writing of the original draft preparation and $\mathrm{CG}$ carried out the writing, review and editing of the manuscript. EVG conducted the validation and supervision of the literature review and writing. All authors read and approved the final manuscript.

\section{Ethics approval and consent to participate}

Not applicable.

\section{Patient consent for publication}

Not applicable.

\section{Competing interests}

The authors declare that they have no competing interests.

\section{References}

1. Abraham RS and Aubert G: Flow cytometry, a versatile tool for diagnosis and monitoring of primary immunodeficiencies. Clin Vaccine Immunol 23: 254-271, 2016.
2. Bonilla FA, Khan DA, Ballas ZK, Chinen J, Frank MM, Hsu JT, Keller M, Kobrynski LJ, Komarow HD, Mazer B, et al: Practice parameter for the diagnosis and management of primary immunodeficiency. J Allergy Clin Immunol 136: 1186-205.e1-78, 2015.

3. Fischer A, Provot J, Jais JP, Alcais A and Mahlaoui N; members of the CEREDIH French PID study group: Autoimmune and inflammatory manifestations occur frequently in patients with primary immunodeficiencies. J Allergy Clin Immunol 140: 1388-1393.e8, 2017.

4. Picard C, Bobby Gaspar H, Al-Herz W, Bousfiha A, Casanova JL, Chatila T, Crow YJ, Cunningham-Rundles C, Etzioni A, Franco JL, et al: International union of immunological societies: 2017 primary immunodeficiency diseases committee report on inborn errors of immunity. J Clin Immunol 38: 96-128, 2018.

5. Bousfiha A, Jeddane L, Picard C, Al-Herz W, Ailal F, Chatila T, Cunningham-Rundles C, Etzioni A, Franco JL, Holland SM, et al: Human inborn errors of immunity: 2019 update of the IUIS phenotypical classification. J Clin Immunol 40: 66-81, 2020.

6. Tangye SG, Al-Herz W, Bousfiha A, Chatila T, Cunningham-Rundles C, Etzioni A, Franco JL, Holland SM, Klein C, Morio T, et al: Human inborn errors of immunity: 2019 update on the classification from the international union of immunological societies expert committee. J Clin Immunol 40: 24-64, 2020.

7. Condino-Neto A and Espinosa-Rosales FJ: Changing the lives of people with primary immunodeficiencies (PI) with early testing and diagnosis. Front Immunol 9: 1439, 2018.

8. Stray-Pedersen A, Sorte HS, Samarakoon P, Gambin T, Chinn IK, Coban Akdemir ZH, Erichsen HC, Forbes LR, Gu S, Yuan B, et al: Primary immunodeficiency diseases: Genomic approaches delineate heterogeneous Mendelian disorders. J Allergy Clin Immunol 139: 232-245, 2017.

9. Primary Immunodeficiencies (PID) Driving Diagnosis for Optimal Care in Europe. European Reference Paper http://worldpiweek.org/sites/default/files/basic_page_documents/PI_ European_Reference_Paper.pdf.(accessed on May 1, 2020).

10. Immune Deficiency Foundation: Primary Immune Deficiency Diseases in America: 2007. The Third National Survey of Patients. Prepared by: Abt SRBI, Inc. May 1, 2009.https://primaryimmune. org/wp-content/uploads/2011/04/Primary-Immunodeficiency-Diseasesin-America-2007The-Third-National-Survey-of-Patients.pdf. (accessed on 26 April 2020).

11. Chapel H, Prevot J, Gaspar HB, Español T, Bonilla FA, Solis L and Drabwell J; Editorial Board for Working Party on Principles of Care at IPOPI: Primary immune deficiencies-principles of care. Front Immunol 5: 627, 2014.

12. Suarez F, Mahlaoui N, Canioni D, Andriamanga C, Dubois d'Enghien C, Brousse N, Jais JP, Fischer A, Hermine O and Stoppa-Lyonnet D: Incidence, presentation, and prognosis of malignancies in ataxia-telangiectasia: A report from the French national registry of primary immune deficiencies. J Clin Oncol 33: 202-208, 2015.

13. Shapiro RS: Malignancies in the setting of primary immunodeficiency: Implications for hematologists/oncologists. Am J Hematol 86: 48-55, 2011.

14. Grimbacher B, Warnatz K, Yong PFK, Korganow AS and Peter HH: The crossroads of autoimmunity and immunodeficiency: Lessons from polygenic traits and monogenic defects. J Allergy Clin Immunol 137: 3-17, 2016.

15. de Jesus AA, Canna SW, Liu Y and Goldbach-Mansky R: Molecular mechanisms in genetically defined autoinflammatory diseases: Disorders of amplified danger signaling. Annu Rev Immunol 33: 823-874, 2015.

16. Jonkman-Berk BM, van den Berg JM, Ten Berge IJ, Bredius RG, Driessen GJ, Dalm VA, van Dissel JT, van Deuren M, Ellerbroek PM, van der Flier M, et al: Primary immunodeficiencies in the Netherlands: National patient data demonstrate the increased risk of malignancy. Clin Immunol 156: 154-162, 2015.

17. Comrie WA and Lenardo MJ: Molecular classification of primary immunodeficiencies of $\mathrm{T}$ lymphocytes. Adv Immunol 138: 99-193, 2018.

18. Gug C, Gorduza EV, Lăcătuşu A, Vaida MA, Bîrsăşteanu F, Puiu M and Stoicănescu D: CHARGE syndrome associated with de novo (I1460Rfs*15) frameshift mutation of CHD7 gene in a patient with arteria lusoria and horseshoe kidney. Exp Ther Med 20: 479-485, 2020. 
19. Mäkitie O and Vakkilainen S: Cartilage-hair hypoplasia-anauxetic dysplasia spectrum disorders. In: GeneReviews ${ }^{\circledR}$ [Internet]. Adam MP, Ardinger HH, Pagon RA, et al (eds). University of Washington, Seattle, WA, 1993-2020. 2012 Mar 15 [Updated 2020 Aug 6]. https://www.ncbi.nlm.nih.gov/books/NBK84550/ (accessed on 17 April 2020).

20. Nagy R, Wang H,Albrecht B, WieczorekD, Gillessen-Kaesbach G, Haan E, Meinecke P, de la Chapelle A and Westman JA: Microcephalic osteodysplastic primordial dwarfism type I with biallelic mutations in the RNU4ATAC gene. Clin Genet 82 : 140-146, 2012.

21. HGNC Database: HUGO Gene Nomenclature Committee (HGNC), European Molecular Biology Laboratory, European Bioinformatics Institute (EMBL-EBI), Wellcome Genome Campus, Hinxton, Cambridge CB10 1SD, United Kingdom. Available online: https://www.genenames.org/(accessed on April 2020).

22. Savage SA: Dyskeratosis Congenita. In: GeneReviews ${ }^{\circledR}$ [Internet]. Adam MP, Ardinger HH, Pagon RA, et al (eds). University of Washington, Seattle, WA, 1993-2020. 2009 Nov 12 [Updated 2019 Nov 21]. Available from: https://www.ncbi.nlm. nih.gov/books/NBK22301/ Accessed April 17, 2020.

23. The UniProt Consortium: UniProt: A worldwide hub of protein knowledge. Nucleic Acids Res 47: D506-D515, 2019.

24. Al-Herz W, Bousfiha A, Casanova JL, Chatila T, Conley ME, Cunningham-Rundles C, Etzioni A, Franco JL, Gaspar HB, Holland SM, et al: Primary immunodeficiency diseases: An update on the classification from the international union of immunological societies expert committee for primary immunodeficiency. Front Immunol 5: 162, 2014

25. Mäkitie O, Pukkala E, Teppo L and Kaitila I: Increased incidence of cancer in patients with cartilage-hair hypoplasia. J Pediatr 134: 315-318, 1999.

26. Abdel-Salam GM, Abdel-Hamid MS, Issa M, Magdy A, El-Kotoury A and Amr K: Expanding the phenotypic and mutational spectrum in microcephalic osteodysplastic primordial dwarfism type I. Am J Med Genet A 158A: 1455-1461, 2012.

27. Jung S, Lee S, Kim S and Nam H: Identification of genomic features in the classification of loss- and gain-of-function mutation. BMC Med Inform Decis Mak 15 (Suppl 1): S6, 2015.

28. Notarangelo LD and Fleisher TA: Targeted strategies directed at the molecular defect: Toward precision medicine for select primary immunodeficiency disorders. J Allergy Clin Immunol 139: 715-723, 2017

29. Weinreich MA, Vogel TP, Rao VK and Milner JD: Up, down, and all around: Diagnosis and treatment of novel STAT3 variant. Front Pediatr 5: 49, 2017

30. Alonso-Bello CD, Jiménez-Martínez MD, Vargas-Camaño ME, Hierro-Orozco S, Ynga-Durand MA, Berrón-Ruiz L, Alcántara-Montiel JC,Santos-Argumedo L,Herrera-Sánchez DA, Lozano-Patiño F and Castrejón-Vázquez MI: Partial and transient clinical response to omalizumab in IL-21-induced low STAT3-phosphorylation on Hyper-IgE syndrome. Case Reports Immunol 2019: 6357256, 2019.

31. Hafsi $W$ and Yarrarapu SNS: Job Syndrome (Hyperimmunoglobulin E). [Updated 2020 Jul 17] In: StatPearls. [Internet] StatPearls Publishing, Treasure Island, FL, 2020 Jan. Available from https://www.ncbi.nlm.nih. gov/books/NBK525947/ Accessed April 25, 2020.

32. Jhamnani RD and Rosenzweig SD: An update on gain-of-function mutations in primary immunodeficiency diseases. Curr Opin Allergy Clin Immunol 17: 391-397, 2017.
33. Rezaei N, Bonilla FA, Sullivan KF, De Vries E, Bousfiha AA, Puck J and Orange J: An introduction to primary immunodeficiency diseases. In: Rezaei N, Aghamohammadi A, Luigi ND. (eds.). Primary Immunodeficiency Diseases. Springer, Berlin, Heidelberg, pp1-81, 2017.

34. Arkwright PD and Gennery AR: Ten warning signs of primary immunodeficiency: A new paradigm is needed for the 21st century. Ann N Y Acad Sci 1238: 7-14, 2011.

35. Subbarayan A, Colarusso G, Hughes SM, Gennery AR, Slatter M, Cant AJ and Arkwright PD: Clinical features that identify children with primary immunodeficiency diseases. Pediatrics 127: 810-816, 2011.

36. Collin M, Bigley V, Haniffa M and Hambleton S: Human dendritic cell deficiency: The missing ID? Nat Rev Immunol 11: 575-583, 2011.

37. Nelson KS and Lewis DB: Adult-onset presentations of genetic immunodeficiencies: Genes can throw slow curves. Curr Opin Infect Dis 23: 359-364, 2010.

38. Gug C, Huțanu D, Vaida M, Doroş G, Popa C, Stroescu R, Furău G, Furău C, Grigoriță L and Mozos I: De novo unbalanced translocation $\mathrm{t}(15 ; 22)(\mathrm{q} 26.2 ; \mathrm{q} 12)$ with velo-cardio-facial syndrome: A case report and review of the literature. Exp Ther Med 16: 3589-3595, 2018.

39. de Miranda NF, Björkman A and Pan-Hammarström Q: DNA repair: The link between primary immunodeficiency and cancer. Ann N Y Acad Sci 1246: 50-63, 2011.

40. Leechawengwongs E and Shearer WT: Lymphoma complicating primary immunodeficiency syndromes. Curr Opin Hematol 19: 305-312, 2012.

41. Casey JP, Nobbs M, McGettigan P, Lynch S and Ennis S: Recessive mutations in MCM4/PRKDC cause a novel syndrome involving a primary immunodeficiency and a disorder of DNA repair. J Med Genet 49: 242-245, 2012.

42. Karalis A, Tischkowitz M and Millington GW: Dermatological manifestations of inherited cancer syndromes in children. $\mathrm{Br}$ J Dermatol 164: 245-256, 2011.

43. Byun M, Ma CS, Akçay A, Pedergnana V, Palendira U, Myoung J, Avery DT, Liu Y, Abhyankar A, Lorenzo L, et al: Inherited human OX40 deficiency underlying classic Kaposi sarcoma of childhood. J Exp Med 210: 1743-1759, 2013.

44. Leroy S, Moshous D, Cassar O, Reguerre Y, Byun M, Pedergnana V, Canioni D, Gessain A, Oksenhendler E, Fieschi C, et al: Multicentric Castleman disease in an HHV8-infected child born to consanguineous parents with systematic review. Pediatrics 129: e199-e203, 2012.

45. Adam MP, Hudgins L and Hannibal M: Kabuki Syndrome. In: GeneReviews ${ }^{\circledR}$. [Internet]. Adam MP, Ardinger HH, Pagon RA, et al (eds). GeneReviews, University of Washington, Seattle, Seattle, WA, pp1993-2020. 2011 Sep 1. [Updated 2019 Oct 21]. Available from https://www.ncbi.nlm.nih. gov/sites/books/NBK62111/. Accessed April 26, 2020.

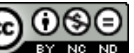

This work is licensed under a Creative Commons Attribution-NonCommercial-NoDerivatives 4.0 International (CC BY-NC-ND 4.0) License. 